\title{
Adoption of Internet and Web Technology for Hotel Marketing: A Study of Hotels in Thailand
}

\author{
Suree Khemthong and Linda M. Roberts \\ Victoria University, Australia
}

\begin{abstract}
This paper examines the effect of three groups of characteristics: organisational, technological, and environmental on the adoption of Internet and Web based marketing activities (IWMA) in the hotel industry by using data collected from a sample of 152 hotels in Thailand. The adoption of IWMA has been categorised into two levels: 1) non-early adopter hotels, and 2) early adopter hotels. The results indicate that Thai hotels that adopted IWMA at the early adopter stage were larger in size, and more likely to be more ready to adopt IWMA than non-early adopter hotels were. Managers of Thai hotels in the early adopter stage were more likely to perceive the benefits and recognise compatibility when adopting IWMA than were managers in the non-early adopter hotels. Customer power and level of government support were considered to be the push factors for hotels in the use of IWMA at the early adopter stage more than for non-early adopter hotels.
\end{abstract}

Key words: Adoption, Internet, Web Technology, Hotel, Marketing

\section{Introduction}

In recent years, the development of the Internet has increased dramatically and many countries in the world have made efforts to improve their Internet services. On the demand side, the Internet consumer base increases globally every day. Consequently, the use of Internet and Web technologies is important and is becoming a direct marketing tool for improving the success of a business in the online environment. In the hotel industry, marketers are taking full advantage to capitalise on this opportunity. As mentioned by Carroll and Siguaw (2003, p. 38), "By 2005, an estimated 1 in 5 hotel bookings will be made online, up from 1 in 12 in 2002". In addition, according to a research conducted by PhoCusWrigt and reported by Mclean (2005) that online hotel sales were predicted to reach $\$ 24$ billion, $27 \%$ of all hotel booking revenue, by 2006 .

Copyright (C) 2006 Victoria University. This document has been published as part of the Journal of Business Systems, Governance and Ethics in both online and print formats. Educational and non-profit institutions are granted a nonexclusive licence to utilise this document in whole or in part for personal or classroom use without fee, provided that correct attribution and citation are made and this copyright statement is reproduced. Any other usage is prohibited without the express permission of the
Although the trend of Internet commerce is increasing worldwide, there is still a gap between developing and developed countries in the use of Internet and Web technologies in online business. According to a report of e-readiness research (Economist Intelligence Unit, 2005), which rates each country's preparedness for e-business, Thailand ranks 
$44^{\text {th }}$ out of 60 countries worldwide. Specifically, only $12.7 \%$ of the Thai population used the Internet in 2005 (the Internet World Stats, 2006). It seems that e-commerce in Thailand falls short when compared to neighbouring nations (ITU, 2002).

In fact, tourism is a way for Thailand to attract foreign currency and expand employment. Preliminary studies found that the use of Internet and Web technologies by Thai hotels was primarily for advertising, not for providing a fully interactive site with the full range of marketing functions, particularly e-commerce features (Khemthong et al., 2005). It is, therefore, important to understand the facilitating and inhibiting factors supporting the adoption and diffusion of the Internet and Web technologies for hotel marketing in Thai hotels.

The main purpose of this paper is to examine the effect of three groups of characteristics: organisational, technological, and environmental on the adoption of Internet and Web based marketing activities (IWMA) in the Thai hotel industry. This paper is structured as follows: firstly, a review of the relevant innovation and hospitality literature is presented; then research hypotheses are proposed; thirdly, methodology and results are presented; and finally, discussion, implications and recommendations, and conclusions are offered.

\section{Innovation Literature}

Many different factors have been identified in previous studies as affecting technological innovation adoption in an organisation, and can be categorised into three main groups of characteristics: organisational, innovation, and environmental. Table 1 summarise factors affecting technological innovation adoption in an organisation.

\begin{tabular}{|l|c|c|c|}
\hline \hline \multicolumn{3}{|c|}{ Table 1: Summary of groups of factors identified from previous studies } \\
\hline \hline \multirow{2}{*}{ Authors } & \multicolumn{3}{c|}{ Groups of Factors } \\
\cline { 2 - 4 } & Organisational & Environmental & Innovation \\
\hline \hline Kimberly \& Evanisko (1981) & $\mathrm{X}$ & $\mathrm{X}$ & $\mathrm{X}$ \\
\hline Grover (1993) & $\mathrm{X}$ & $\mathrm{X}$ & $\mathrm{X}$ \\
\hline Iacovou et al. (1995) & $\mathrm{X}$ & $\mathrm{X}$ & $\mathrm{X}$ \\
\hline Chau \& Tam (1997) & $\mathrm{X}$ & $\mathrm{X}$ & $\mathrm{X}$ \\
\hline Thong (1999) & $\mathrm{X}$ & & $\mathrm{X}$ \\
\hline Kendall et al. (2001) & & $\mathrm{X}$ & $\mathrm{X}$ \\
\hline Scupola (2003) & $\mathrm{X}$ & $\mathrm{X}$ \\
\hline Seyal et al. (2003) & $\mathrm{X}$ & & $\mathrm{X}$ \\
\hline \hline
\end{tabular}

The theoretical foundation for most technology adoption research has been based on the diffusion of innovation literature (Tornatzky and Klein, 1982; Rogers, 1995; Tornatzky and Fleischer, 1990). There are five types of innovation adopters: 1) innovators, 2) early adopters, 3) early majority, 4) late majority, and 5) laggards (Rogers, 1995). Innovators are the fastest adopters while laggards are the slowest adopters. Thus, a theoretical basis for this study is found in the organisational innovation literature, through innovation theory. In this study, for the adoption of IWMA hotels have been categorised into two groups based on the extent of IWMA adoption: 1) early adopter hotels, and 2) nonearly adopter hotels. Early adopter hotels have e-mail, Web site for advertising, receive online bookings, confirm bookings immediately, receive payment by a security system, and complete transactions on their Web site. Non-early adopter hotels include: hotels that have no Web site and only have e-mail; hotels that have e-mail and a basic Web page for advertising; and hotels that have e-mail and a Web site for receiving online bookings.

\section{Hospitality Literature}

Several different issues that have been investigated on the diffusion of ICTs and e-commerce in the hospitality industry are reported in the literature. These issues can be separated into three groups including: 1) characteristics of the property including size, chain membership, and management 
structure (Siguaw et al., 2000; Paraskevas and Buhalis, 2002; Sigala, 2003; Mistilis et al., 2004), 2) characteristics of owners/ managers including education level, age, technical expertise and training (Van Hoof and Combrink, 1998; Van Hoof et al., 1999; Mistilis et al., 2004), and 3) perceived benefits and barriers including perceived cost, benefits or advantages, and barriers for the use of ICTs (Garces et al., 2004; Buhalis and Deimezi, 2004). Figure 1 summarises factors affecting technology adoption in the hospitality literature.

Figure 1: Factors identified from hospitality literature as affecting technology adoption in the hospitality industry

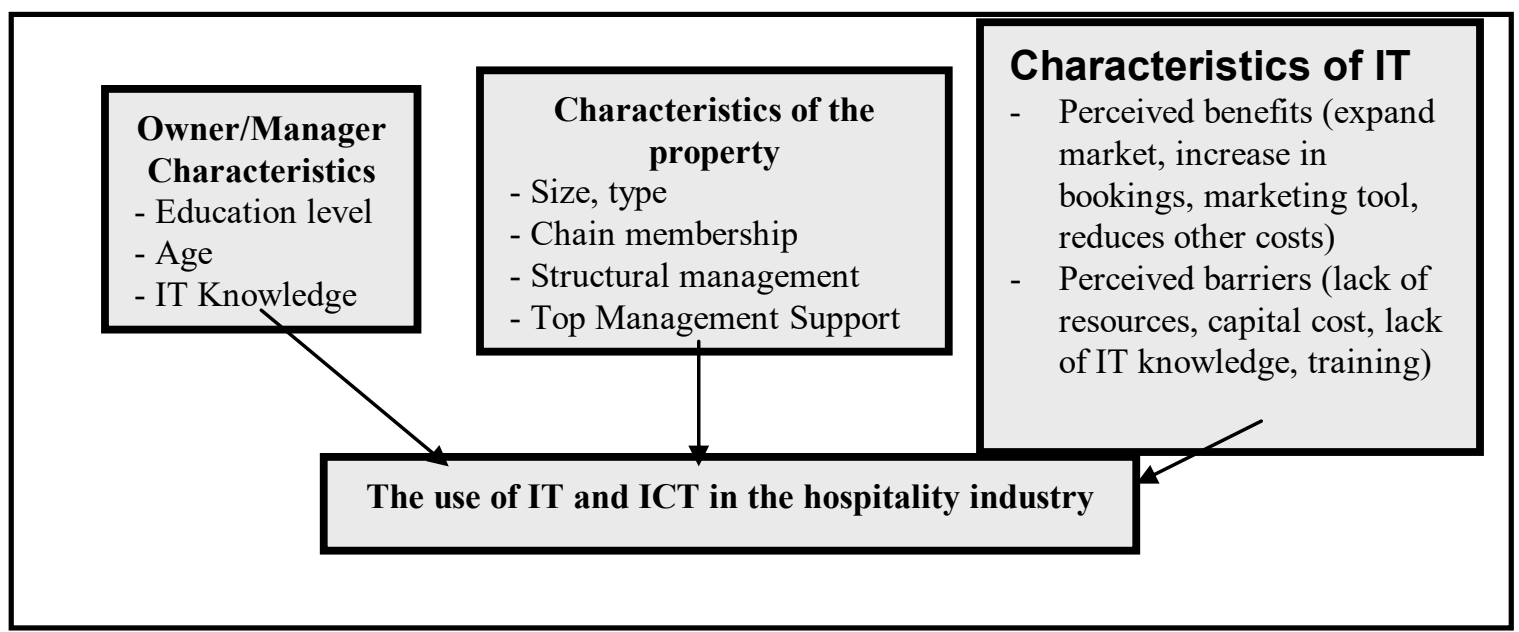

Sources: adapted from Khemthong et al. (2006)

Thus, a conceptual framework of the adoption of Internet and Web based marketing activities in the hotel industry was developed by utilising diffusion of innovation theory and also by incorporating those factors affecting the use of IT in an organisation; a concept readily derived from the organisational innovation and hospitality industry literature. In this study, the proposed conceptual framework incorporates three key groups of factors: organisational, innovation, and environmental (see Table 2).

\begin{tabular}{|l|l|}
\hline \hline \multicolumn{2}{|c|}{ Table 2: Research Variables Used for This Study } \\
\hline \hline \multicolumn{1}{|c|}{ Groups of Factors } & \\
\hline \hline \multirow{4}{*}{ Organisational Factors } & Sariables \\
\cline { 2 - 2 } & Top Management Support \\
\cline { 2 - 2 } & Organisational Readiness \\
\cline { 2 - 2 } & CEO's attitudes \\
\cline { 2 - 2 } Innovation Factors & CEO's IS Knowledge \\
\cline { 2 - 2 } & Perceived Benefits \\
\cline { 2 - 2 } & Perceived Barriers \\
\cline { 2 - 2 } & Compatibility \\
\cline { 2 - 2 } & Complexity \\
\cline { 2 - 2 } & Image \\
\hline \multirow{5}{*}{ Environmental Factors } & Competition Intensity \\
\cline { 2 - 2 } & Customer Power \\
\cline { 2 - 2 } & Level of Government Support \\
\cline { 2 - 2 } & Level of Technology Support \\
\hline \hline
\end{tabular}

Sources: adapted from Khemthong et al. (2006)

Organisational factors include the inherent characteristics of both 1) the hotel in terms of organisational structure (size of hotel), and organisational process (top management support and organisational readiness, and 2) the decision maker (CEO's attitudes and CEO's IS knowledge). Innovation factors include: 1) perceived benefits; 2) barriers; 3) compatibility; 4) complexity; and 5) 
image, which arise from technological innovation adoption theory. Environmental factors for the organisational environment include: 1) competition intensity; 2) customer power; 3) level of government support; and 4) level of technology support, which arise from organisational environment theory.

\section{Research Hypotheses}

\section{Organisational Characteristics}

Organisational characteristics have been frequently used as a key determinant of technological innovation adoption. A number of previous studies have shown that Business size influences the use of the technology (Thong, 1999; Dholakia and Kshetri, 2004). Similarly, hotel characteristics, such as whether the hotel is independent or part of a chain, whether it is luxury, upscale or budget, or how large it is, have all been shown to influence the adoption of technology (Van Hoof et al., 1999; Siguaw, 2000). Several previous studies have shown that top management support is a significant predictor of technology adoption and leads to more successful computer use in both large and small businesses (Tan and Teo, 1998; Seyal, et al., 2003). In addition, Heung (2003) reported that "Management support" is an important factor for travel agencies when they decide to implement e-commerce. Organisational readiness in terms of financial and technological resources has also been shown to be necessary for the use of IT in hospitality organisations (Buhalis and Main, 1998; Heung, 2003). CEOs who have a positive attitude towards adoption of IT have been reported in earlier studies to be more likely to adopt information technology (Thong and Yap, 1995, and Seyal et al., 2003). CEO's IS Knowledge has also been found to be related to adoption of IT in firms (Thong and Yap, 1995; Thong, 1999). Furthermore, Mistilis et al. (2004) reported that ICT knowledge had a strong relationship with ICT adoption in Sydney hotels.

Based on an assessment of these studies, the first hypothesis was proposed:

H1: Organisational factors of size of hotel, level of top management, organisational readiness, CEO's attitude, and CEO's IS knowledge have an effect on the adoption of IWMA in the Thai hotel industry.

\section{Innovation characteristics}

Innovation characteristics are widely and frequently used as a key determinant of innovation adoption. As mentioned earlier, Rogers (1995) identified the five attributes of an innovation that can influence innovation adoption: 1) relative advantage, 2) complexity, 3) compatibility, 4) trialability, and 5) observability. Several prior studies have shown that relative advantage or perceived benefits was the best predictor of the adoption innovation (e.g. Iacovou et al., 1995; Kendall, et al., 2001). Similarly, compatibility was found in many studies to be associated with the adoption of innovation (e.g. Thong, 1999; Seyal et al., 2003). Rogers (1995) noted that the complexity of an innovation is negatively related to its rate of adoption. O'Connor and Frew (2004) reported that ease of use is an important factor for the hotel industry in the adoption of electronic channels of distribution. Also, Anckar and Walden (2001) found that barriers in terms of lacking financial resources, lacking IT knowledge, resistance to change and location in peripheral regions each had an effect on the use of IT and the Internet in small and medium hospitality organisations (SMHOs). Moore and Benbasat (1991) suggested that image associated with users of information technology (IT) and IT itself is an important determinant of the adoption decision.

Based on the above, the second hypothesis was proposed:

H2: Innovation factors of perceived benefits, compatibility, complexity, image, and perceived barriers each have an effect on the adoption of IWMA in the Thai hotel industry. 


\section{Environmental characteristics}

Environmental characteristics are important factors that have also been investigated in many previous studies (e.g. Tan and Teo, 2000; Scupola, 2003). The competitive environment has been found to be associated with the adoption of IT in several studies (Scupola, 2003; Lertwongsatien and Wongpinunwatana, 2003). Buhalis and Main (1998) reported that customer demand is the pull factor for small and medium hospitality organisations (SMHOs) to use IT. Previous studies have suggested that a government can encourage a country's private sector to adopt e-commerce by providing supporting infrastructure, legal and regulatory frameworks, and e-commerce use directions (Kuan and Chau, et al., 2001). Government intervention and public administration were both found to be very important for the adoption and implementation of technological innovations (Scupola, 2003; Wang and Cheung, 2004). Also, level of technology support, which refers to the supporting of technological infrastructures that are easily and readily available for the use of IWMA, was found to be significantly associated with organisational innovation adoption (Tan and Teo, 2000).

Based upon these, the third hypothesis was proposed:

H3: Environmental factors of customer power, competitive intensity, level of Government support and level of technology support have an effect on the adoption of IWMA in the Thai hotel industry.

\section{Methodology}

Following an extensive review of the innovation and hospitality literature exploratory in-depth interviews were conducted with managers of hotels in Thailand to place the findings from the literature review into the Thai context. A questionnaire survey was then selected as the main method for data collection on which to test the three hypotheses.

As there was no previous research on the adoption of Internet and Web based marketing activities by the hotel industry in Thailand has been reported in the literature, exploratory research was employed to explore the local context. Therefore, during the months of September and October 2004, in-depth semistructured interviews (exploratory study) were conducted at each of six hotels in Thailand. Each interview took approximately one hour to complete. Participants were two general managers, one executive assistant manager, three marketing managers and one front office manager. The in-depth interviews questions were designed to determine:

- General information about firm demographics;

- Main reasons and problems influencing the adoption of Internet and Web based marketing activities in the hotel industry in Thailand;

- Benefits and cost of Internet and Web based marketing activities adoption in the hotel industry in Thailand;

- Environmental factors in Thailand that support the use of the Internet and Web based marketing activities.

The results of these interviews (e.g. opinions, suggestions, and experiences) provided direction as to what factors were imperative for the hotel industry, and these were used to supplement the findings from the literature review in the design the survey questionnaire.

Hotels selected for this study were identified utilising the definition of hotels from the Thai Hotel Association's Directory (2003-2004). The term of "Hotel" as used by the Thai Hotel Association includes hotels, motels, inns, and resorts that have a hotel licence, provide guest accommodation, and meals and beverages through a coffee shop, restaurant, or club. This study focused on the hotels located in three cities in Thailand, Bangkok, Phuket, and Chiang Mai. These regions were chosen because they are tourist destinations, and had both a sufficient number and variety of suitable hotels for this study. There was a total population of 327 hotels in the three areas of Thailand (Directory of Thai Hotel Association, 
2003-2004). Due to the relatively small population, this study surveyed the entire population thereby providing data that were not only accurate but also precise (Zikmund, 2003).

The quantitative survey, which was selected as the main method of data collection for this study, was conducted in May 2005. The package sent to the hotels in the sample contained three items: a covering letter, one copy of the questionnaire, and a prepaid reply envelope was mailed to each of the 327 general managers of the hotels in Bangkok, Phuket, and Chiang Mai in Thailand. The cover letter explained the purpose of the survey and asked the general manager to return the completed questionnaire within three weeks in the prepaid reply envelope. In order to increase the response rate, a follow-up procedure was also employed in this study that involved a second mailing of questionnaires to those hotels that had not responded within the three weeks. The first mailing yielded 102 responses and from the second mailing 50 more responses were received. In the end, nearly half (152) of the questionnaires were completed and returned after two mailings. This represented a response rate after two mailings of $46.5 \%(152 / 327)$, which is an acceptable percentage response rate (Cavana et al., 2001).

The questions in the survey questionnaire were designed with a closed format. Dichotomous scales and categorical scales were used for the questions regarding hotel characteristics and hotel respondents. For questions on the issues regarding the factors affecting the adoption of IWMA in the hotel industry, respondents were asked to rate the extent of their agreement or disagreement with the statements provided on a seven-point Likert rating scale, ranging from $1=$ strongly disagree, $2=$ disagree, $3=$ slightly disagree, $4=$ neither disagree nor agree, $5=$ slightly agree, $6=$ agree to $7=$ strongly agree. The full questionnaire is provided in Appendix I.

In order to ensure that the instruments developed for this study were precise and accurate measurements, it was necessary to assess the "goodness" of measures. A pilot study was conducted in April 2005 with 20 respondents who were hotel general managers, owners, and marketing managers in Thai hotels in two tourist resorts in Thailand, Pattaya and Hua-Hin. This was done after correcting the questionnaire by using the comments and feedback from the preliminary pre-test with 19 research professionals at Victoria University.

In addition, two forms of statistical analyses were used to test instrument validity: Alpha Internal Consistency Reliability, and Common Factor Analysis. The reliability coefficients for the alpha internal consistency reliability test, with the exception of that for organisational readiness, met Nunnally's guideline of 0.60 and above, thus confirming reliability of the research variables. Factor analysis was used to test the validity of ideas about the items in order to decide how the items should be grouped together. Therefore, if the variable consisted of only one item, such as size of hotel and CEO's IS knowledge, it was not placed in a group by itself. The size of hotel was measured by the number of hotel rooms. Most of the factor loadings are greater than the cut-off point of 0.50 as recommended by Nunnally (1978), with the exception of only one item (item 35: barrier), the value for which was still very close to $0.50(0.468)$, as shown in Table 3 . Hence, dimensions of the construct were confirmed to group correctly and met the expected concepts as theorised. 


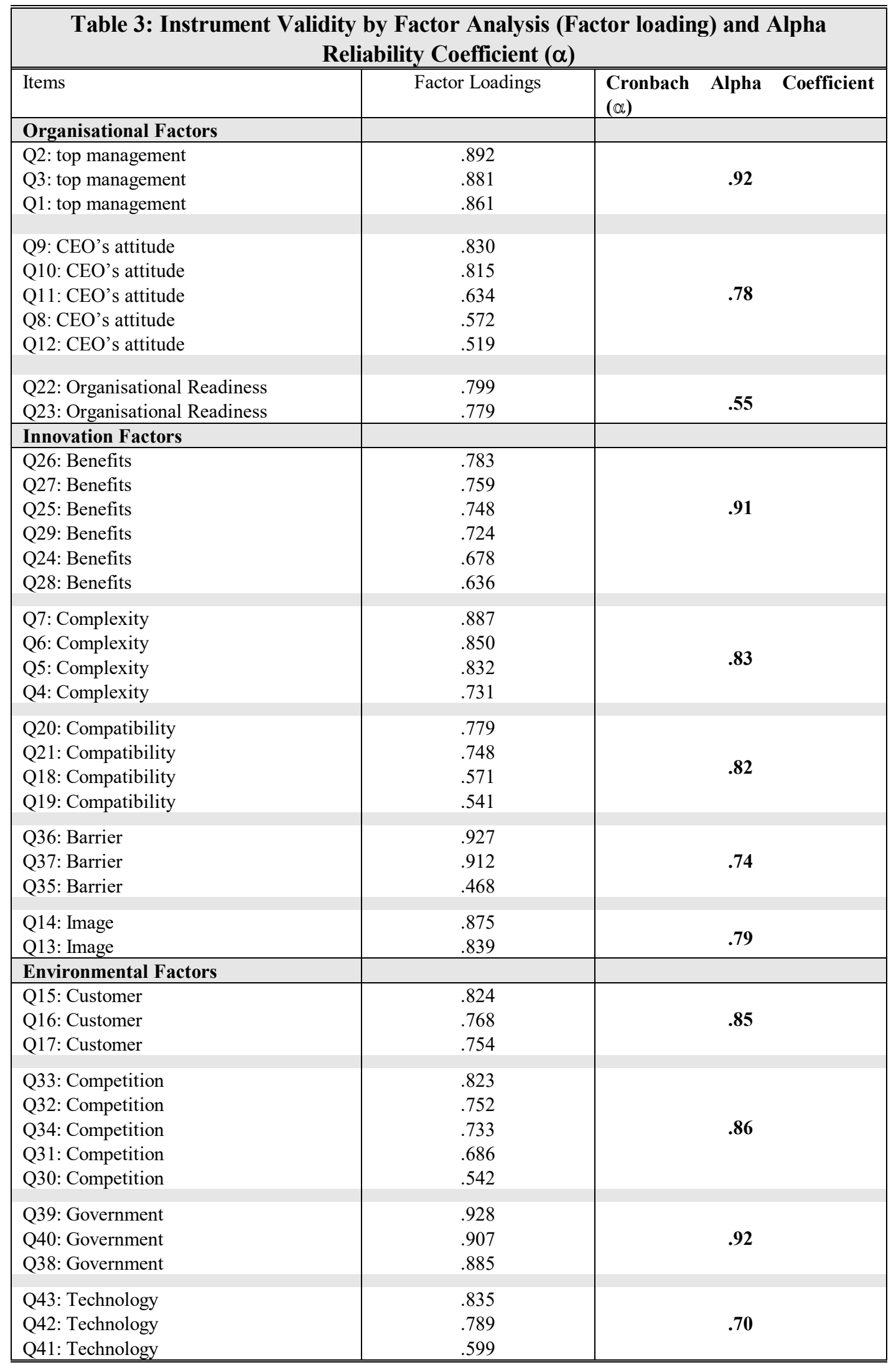

Note: The survey questionnaire is provided in Appendix 1, and the questions listed in the above table can be identified by number in Part II. 


\section{Results}

\section{Characteristics of Thai Hotel Samples}

In Table 4 the characteristics of the 152 hotels and the respondents in the sample from the three cities in Thailand, Bangkok, Phuket, and Chiang Mai are summarised. The greater number of hotels in the sample in Thailand were located in Bangkok (42.8\%), followed by Phuket (36.2\%), and Chiang Mai $(21.0 \%)$, respectively.

\begin{tabular}{|c|c|c|c|}
\hline \multicolumn{4}{|c|}{ Table 4: Demographic of Thai Hotels and Respondents } \\
\hline $\begin{array}{c}\text { Hotel \& Respondents } \\
\text { Characteristics } \\
\end{array}$ & Categories & $\mathbf{N}$ & $\%$ \\
\hline \multirow[t]{3}{*}{ Location } & Bangkok & 65 & 42.8 \\
\hline & Phuket & 55 & 36.2 \\
\hline & Chiang Mai & 32 & 21.0 \\
\hline \multirow{7}{*}{ Numbers of Hotel's rooms } & Less than 51 rooms & 24 & 15.8 \\
\hline & $51-100$ rooms & 24 & 15.8 \\
\hline & $101-150$ rooms & 15 & 9.9 \\
\hline & $151-200$ rooms & 15 & 9.9 \\
\hline & 201-300 rooms & 38 & 25.0 \\
\hline & $301-400$ rooms & 14 & 9.2 \\
\hline & More than 400 rooms & 22 & 14.4 \\
\hline \multirow{6}{*}{$\begin{array}{l}\text { Duration of using Internet } \\
\text { and Web technologies }\end{array}$} & Less than 1 year & 8 & 5.3 \\
\hline & $1-3$ years & 43 & 28.3 \\
\hline & $4-5$ years & 49 & 32.2 \\
\hline & $6-10$ years & 40 & 26.3 \\
\hline & More than 10 years & - & - \\
\hline & Missing & 12 & 7.9 \\
\hline \multirow{4}{*}{$\begin{array}{l}\text { Level of using Internet and } \\
\text { Web technologies }\end{array}$} & - Having e-mail, no Web Site & 4 & 2.6 \\
\hline & - Having e-mail and basic Web page & 15 & 9.9 \\
\hline & $\begin{array}{l}\text { - Having e-mail, own Web site, and receiving } \\
\text { online booking }\end{array}$ & 105 & 69.1 \\
\hline & $\begin{array}{l}\text { - Having e-mail, own Web site, and making } \\
\text { complete transactions }\end{array}$ & 28 & 18.4 \\
\hline \multirow[t]{6}{*}{ Position of Respondents } & General Manager & 76 & 50.0 \\
\hline & Marketing Manager & 27 & 17.8 \\
\hline & Owner & 14 & 9.2 \\
\hline & Operations Manager & 2 & 1.3 \\
\hline & Front Office Manager & 1 & 0.7 \\
\hline & Others & 32 & 21.0 \\
\hline \multirow[t]{5}{*}{ Education } & TAFE & 22 & 14.5 \\
\hline & Bachelor's & 79 & 52.0 \\
\hline & Master's & 41 & 27.0 \\
\hline & Ph.D. & 2 & 1.3 \\
\hline & Missing & 8 & 5.2 \\
\hline
\end{tabular}

Source: Data drawn from survey questionnaire (part I) responses.

About one-quarter (25\%) of Thai hotels were in the size range of 201-300 rooms and just less than onequarter $(23.6 \%)$ had more than 301 rooms. It seems that the majority of the Thai hotels had more than 100 rooms. About one-third (32.2\%) of the Thai hotels had used the Internet and Web technologies for hotel marketing for 4-5 years. Nearly three-quarters (69.1\%) of the Thai hotels had e-mail and their own Web sites which could receive online bookings, while $18.4 \%$ of the hotels had e-mail, their own Web sites, and could complete transactions. Only about $2.6 \%$ of the Thai hotels had only e-mail. Thus, it may be inferred that most of the Thai hotels were at the non-early adopter stage in their use of IWMA. 
The highest level of education that Thai hotel managers had achieved was a master's degree (27\%) with the greater proportion having a bachelor's degree $(52 \%)$, and a smaller proportion having TAFE certification $(14.5 \%)$. This implies that the majority of Thai hotel managers had a university degree. About half $(50 \%)$ of the Thai respondents held the current position of general manager of their hotels, while $17.8 \%$ were hotel marketing managers. The majority of respondents were the general managers of the hotels in which they worked. Thus, the data were obtained from a sample of 152 senior managers including managing directors, general managers or marketing directors of the hotels, who make the decisions regarding their hotel's marketing activities.

\section{Hypothesis Testing}

Three statistic techniques were utilised for testing hypotheses; 1) multivariate analysis of variance (MANOVA), 2) one-way analysis of variance (ANOVA), and 3) independent sample $t$-test.

In order to ensure that there was no problem with multi-collinearity among the research variables, Pearson correlation matrix was constructed to assess the strength of the correlations among the independent variables. The presence of high multi-collinearity would make determining the contribution of the effect of each independent variable on the dependent variable difficult as it indicates that the effects of the independent variables are mixed or confounded. None of the squared correlations are close enough to 0.80 to suggest a problem with multi-collinearity among the research variables, as shown in Appendix II (Hair et al., 1998).

MANOVA was used as a preliminary analysis to find out if there were any differences in factors affecting the use of IWMA between the different groups of hotels in terms of non-early adopter and early adopter hotels. When a significant difference in the identified factors between these two groups was found, one-way ANOVA was used to follow up the analysis of MANOVA. ANOVA was used to find out which of the factors differed significantly across the groups or discriminated the groups (Field, 2005). The $t$-test was used to compare mean scores of two groups of hotels, non-early adopter hotels and early adopter hotels, in order to confirm and support the results of the one-way ANOVA.

The results of four multivariate test statistics presented in Table 5 show that the value of Pillai's trace, Wilks's Lambda, Hotelling's Trace, and Roy's Largest Root are less than 0.05 (.046), which reach the criterion for significance of 0.05 . Thus from these results it may be concluded that there were statistically significant differences between non-early adopter and early adopter hotels in Thailand in the factors affecting the use of IWMA.

The results of one-way ANOVA also shown in Table 5 provide support for three groups of hypotheses: two groups for hypothesis 1 (H1.1, and H1.3), two groups for hypothesis 2 (H2.1, and H2.3), and two groups for hypothesis 3 (H3.1, and H3.3). The results show that early adopter and non-early adopter hotels were significantly different in terms of the size of hotel, organisational readiness, perceived benefits and compatibility towards the use of IWMA, customer power, and level of Government support. 


\begin{tabular}{|c|c|c|c|c|c|c|}
\hline \multicolumn{7}{|c|}{ Table 5: Hypothesis Testing by MANOVA, One-Way ANOVA, and t-test } \\
\hline \multirow{2}{*}{$\begin{array}{l}\text { Factors } \\
\text { nal factors }\end{array}$} & $\begin{array}{l}\text { Non-early } \\
\text { Adopter }\end{array}$ & $\begin{array}{c}\text { Early } \\
\text { Adopter }\end{array}$ & \multicolumn{2}{|c|}{ ANOVA } & \multicolumn{2}{|c|}{ t-test } \\
\hline & \multicolumn{2}{|c|}{ Mean } & F Statistic & Sig. & t-value & $P$ P-value \\
\hline H1.1: Hotel Size & 3.75 & 5.00 & 9.179 & .003 & -3.030 & .003 \\
\hline H1.2: Top Management Support & 6.32 & 6.65 & 2.979 & .086 & -1.726 & .086 \\
\hline H1.3: Organisational Readiness & 5.23 & 5.75 & 4.168 & .043 & -2.042 & .043 \\
\hline H1.4: CEO's Attitude & 6.31 & 6.55 & 2.498 & .116 & -1.581 & .116 \\
\hline H1.5: CEO's IS Knowledge & 5.56 & 5.89 & 1.855 & .175 & -1.362 & .175 \\
\hline \multicolumn{7}{|l|}{ Innovation factors } \\
\hline H2.1: Perceived Benefits & 5.49 & 6.07 & 6.363 & .013 & -2.522 & .013 \\
\hline H2.2: Perceived Complexity & 5.60 & 5.91 & 2.490 & .117 & -1.578 & .117 \\
\hline H2.3: $\quad$ Perceived & 5.74 & 6.35 & 9.433 & .003 & -4.378 & .000 \\
\hline Compatibility & 4.19 & 4.42 & .615 & .434 & -.784 & .434 \\
\hline $\begin{array}{l}\text { H2.4: Perceived Barriers } \\
\text { H2.5: Image }\end{array}$ & 5.91 & 6.10 & .506 & .478 & -.711 & .478 \\
\hline \multicolumn{7}{|l|}{ Environmental factors } \\
\hline H3.1: Customers Power & 5.77 & 6.23 & 4.264 & .041 & -2.065 & .041 \\
\hline H3.2: Competition Intensity & 5.41 & 5.80 & 3.428 & .066 & -1.851 & .066 \\
\hline Government & 4.60 & 5.33 & 4.666 & .032 & -2.160 & .032 \\
\hline $\begin{array}{l}\text { Support } \\
\text { H3.4: Technology Support }\end{array}$ & 5.99 & 6.25 & 1.996 & .160 & -1.413 & .160 \\
\hline $\begin{array}{l}\text { MANOVA: Pillai's Trace }=.155, \\
\text { Wilks' Lambda }=.845, \mathrm{~F}=1.789, \\
\text { Hotelling's Trace }=.183, \mathrm{~F}=1.78 \\
\text { Roy's Largest Root }=.183, \mathrm{~F}=1 .\end{array}$ & $\begin{array}{l}1.789, \text { Sig }= \\
g=.046 \\
\text { Sig }=.046 \\
\text { Sig }=.046\end{array}$ & & & & & \\
\hline
\end{tabular}

As mentioned the t-test was used to confirm the results of one-way ANOVA. The results of the $t$-test confirmed and provided support for three groups of hypotheses: H1 (H1.1, and H1.3), H2 (H2.1, and $\mathrm{H} 2.3$ ), and $\mathrm{H} 3$ (H3.1, and H3.3).

Based on the results of the one-way ANOVA, and $t$-test, it can be inferred that Thai hotels that adopted IWMA at the early adopter stage were:

- large in size;

- more likely to have higher readiness than non-early adopter hotels;

- more likely to perceive higher benefits towards adoption of IWMA than non-early adopter hotels;

- more likely to perceive higher compatibility towards adoption of IWMA than non early adopter hotels;

- more likely to have higher pressure from their customers than non-early adopter hotels;

- more likely to have a higher level of government support than non-early adopter hotels.

\section{Discussion}

Results from statistical analysis reveal insights into the key factors that influence the use of IWMA in the Thai hotel industry. Overall, the results strongly support the three main groups of hypotheses. It was found that only $18.4 \%$ of Thai hotels were at the early adopter stage. This implies that Thai hotels were still at a stage in developing the technologies for their marketing.

Thai hotels that were at the early adopter stage for IWMA were larger in size, and more likely to be more ready for the adoption of IWMA than non-early adopter hotels were. This finding is in agreement with the technological innovation literature that found that businesses that are bigger in size are more 
likely to adopt IT (e.g. Thong and Yap, 1995; Thong, 1999). In addition, a number of research findings reported in the hospitality literature (e.g. Morrison, et al., 1999; Paraskevas and Buhalis, 2002; Sigala, 2003) revealed that there are differences in the performance of hotel Web sites among hotel categories and hotel sizes (small, medium, and large businesses).

In terms of organisational readiness, most of the Thai hotel managers at the non-early adopter stages were concerned about the budget and employees' IS knowledge as important factors to prepare for the use of IWMA in their hotels. This finding is supported by previous studies (Anckar and Walden, 2001) that found lack of financial resources, and lack of IT knowledge were factors that inhibit small and medium hospitality organisations from fully capitalising on information technology and the Internet.

In terms of innovation factors, it may be inferred that managers of Thai hotels in the early adopter stage were more likely to perceive the benefits and compatibility towards the adoption of IWMA more than were managers in the non-early adopter hotels. This finding is in agreement with the technological innovation literature that found that perceived benefit was the best predictor of the adoption of innovation (e.g. Rogers, 1995; Iacovou et al., 1995; Kendall, et al., 2001). In addition, this finding supports Rogers' suggestion that compatibility of an innovation with a previously introduced idea can influence the adoption of innovation. In addition this finding is in agreement with previous studies (Moore and Benbasat, 1991; Tan and Teo, 2000; Seyal et al., 2003) that have shown that compatibility is associated with the adoption of innovation in an organisation.

In terms of environmental factors, it may be inferred that managers of Thai hotels at the early adopter stage considered that customer power and level of government support were the push factors for their hotels to use IWMA rather than for non-early adopter hotels. The finding is consistent with other studies (Buhalis and Main, 1998) that reported that customer demand is the pull factor for SMHOs to use IT. Specifically, Yeh et al. (2005) found that business travelers had positive perceptions and needs for hotel e-commerce and IT applications. In terms of the level of government support, this finding is supported by previous studies that found that government intervention and public administration were very important for the adoption and implementation of technological innovations (Iacovou et al., 1995; Tan and Teo, 2000; Scupola, 2003).

\section{Implications and Recommendations}

This study has provided evidence that technological innovation theories can be successfully applied to the study of adoption of IWMA in the context of the Thai hotel industry. The proposed model for the adoption of IWMA should provide guidance for Thai hoteliers to evaluate and improve the use of Internet and Web based marketing activities. The results of this study can be used as a guideline for future research in the hotel industry for the examination of the phenomenon in other Asian country settings.

For practitioners or hotel managers, this study highlights the importance of organisational readiness, customer power, and level of government support in influencing the adoption of IWMA in Thailand. Hotel managers should consider their organisational and environmental readiness for the use of IWMA. This study shows that organisational readiness in terms of IT skills and knowledge plays a major role in influencing the development of use of IWMA in the Thai hotel industry. Most hotels at the early adopter stage were more ready for the use of IWMA than hotels at the non-early adopter stage since they gave their staff formal training before adopting IWMA. Hence, further training that focuses on IT knowledge is required and important for employees at non-early adopter hotels to increase their use of IWMA. However, managers of early and non-early adopter hotels should develop their employees' IT skills and knowledge to be in place ready for the competition in a current environment. It is also suggested that in order to enhance their competitiveness, extend their reach to their target customers, and meet the needs of consumers, hotel managers should continuously monitor customer demand and changes in the market using IWMA. 
For policy makers, based on the findings of this study, it is suggested that hoping to be a leader in the tourism industry, the Thai government should increase its attention on improving the technology to make it more advanced and to support resources for industries to connect together. The Thai government should make a contribution to the greater use of the IWMA in the Thai hotel industry through promulgating English language knowledge and computer education, improving infrastructure, opening free trade of service providers, and promotion of the Thai tourism industry.

Finally, four limitations of this study should be mentioned. Firstly, the scope of this study was limited by its population frame, which included hotels in only three cities in Thailand. The sample used for analysis for each level of using the IWMA drawn from the hotel population in the three areas was relatively small. Future research, therefore, should expand on the present study by using samples of hotels located in other areas or countries with varying environments. Secondly, data for this study were collected by the key informant approach. Although using hotel managers or marketing managers as key informants is adequate for producing reliable and valid data (Tan and Litschert, 1994), a future study on the adoption of Internet and Web based marketing activities in the hotel industry could attempt to use multiple informants to obtain a fuller picture of data, and overcome biases that stem from the use of single informants. Thirdly, in terms of instrument design, two of the variables: image and organisational readiness used fewer than three items for measurement, weakening the reliability of the instrument. Future studies should expand these constructs with more items increasing the validity and reliability of the instrument. Finally, in terms of rate of adoption, it was difficult to measure directly the rate of adoption. For this survey, the data regarding the year of adoption of IWMA by the hotel participants was not completed. Most hotel managers answered that they could not remember, or they did not work at that time. As a result, the data were missing. It is suggested that longitudinal studies could be conducted.

\section{Conclusion}

This study has examined the factors affecting the successful adoption and implementation of Internet and Web technologies in hotel marketing in the Thai hotel industry. It concludes that there are three main groups of factors affecting the adoption of IWMA in the Thai hotel industry including 1) organisational in terms of size of hotel, and organisational readiness, 2) innovation factors in terms of benefits and compatibility, and 3) environmental factors in terms of customer power, and level of government support. Benefits and compatibility towards the use of IWMA were the major facilitating factors, whereas lack of IT skills and knowledge was an inhibiting factor for the use of IWMA. Specifically, customer demand was the push factor for Thai hotels in the use of IWMA. Issues relating to the level of Government support play a major role in influencing the development of use of IWMA in the Thai hotel industry.

\section{Bibliography}

Anckar B \& Walden P 2001, 'Introducing Web technology in A Small Peripheral Hospitality Organization', International Journal of Contemporary Hospitality Management, vol. 13, no. 5, pp. 241-250.

Buhalis, D \& Main, H 1998, 'Information Technology in Peripheral Small and Medium Hospitality Enterprises: Strategic Analysis and Critical Factors', International Journal of Contemporary Hospitality Management, vol. 10, no. 5, pp. 198-202.

Buhalis, D \& Deimezi, D 2004, 'E-tourism developments in Greece: Information Communication Technologies Adoption for the Strategic Management of the Greek Tourism Industry', Tourism and Hospitality Research, vol. 5, no. 2, pp. 103-130.

Carrol, B \& Siguaw, J 2003, 'The Evolution of Electronic Distribution: Effects on Hotels and Intermediaries', Cornell Hotel and Restaurant Administration Quarterly, vol. 44, no. 4, pp. 38-50.

Cavana, RY, Delahaye, BL \& Sekaran, U 2001, Applied business research: Qualitative and Quantitative Methods, John Wiley \& Sons, Milton. 
Directory of Thai Hotel Association 2003-2004, Thailand Official Hotel Directory, Bangkok.

Dholakia, RR \& Kshetri, N 2004, 'Factors Impacting the Adoption of the Internet among SMEs', Small Business Economics, vol. 23, no. 4, pp. 311-322.

Economist Intelligence Unit 2005, The 2005 e-readiness rankings [Online Internet] Available: $\mathrm{http} / / \mathrm{www}$.eiu.com accessed 25 June 2005.

Field, A 2005, Discovering Statistics Using SPSS, $2^{\text {nd }}$ edn, Sage Publications, London.

Garces, SA, Gorgemans, S \& Sanchez, AM 2004, 'Implications of the Internet-An Analysis of the Aragonese Hospitality Industry, 2002', Tourism Management, vol. 25, no. 5, pp. 603-613.

Hair, JF, Anderson, RE, Tatham, RL \& Black, WC 1998, Multivariate Data Analysis, $5^{\text {th }}$ edn, Prentice-Hall, New Jersey.

Heung, VCS 2003, 'Barriers to Implementing E-Commerce in the Travel Industry: A Practical Perspective', International Journal of Hospitality Management, vol. 22, no. 1, pp. 111-118.

Iacovou, CL, Benbasat, I \& Dexter, AS 1995, 'Electronic Data Interchange and Small Oganizations: Adoption and Impact of Technology', MIS Quarterly, vol. 5, no. 4, pp. 465-485.

Internet World Stats 2006, World Internet Usage and Population Statistics, Available via http://www.internetworldstats.com/stats3.htm/ accessed by 31 Jan 2006.

ITU 2002, Bits and Bahts: Thailand Internet Case Study, [Online Internet] Available: http// www.itu.int/ITU-D/ict/cs accessed 10 October 2003.

Kendall, J, Tung, LL, Chua, KH, Ng, CHD \& Tan, SM 2001, 'Electronic Commerce Adoption by SMEs in Singapore', Proceeding of the $34^{\text {th }}$ Hawaii International Conference on System Sciences, Hawaii, 1-10.

Khemthong, S, Roberts, L \& Whitelaw, P 2005, 'An Analysis of Hotel Web Sites: A Study of Hotels in Thailand and Australia', Proceeding of the Tourism Enterprise Strategies (TES): Thriving-and Surviving-in an Online Era Conference $11^{\text {th }}$ and $12^{\text {th }}$ July, Melbourne, pp. 117-134.

Khemthong, S, Roberts, L \& Whitelaw, P 2006, 'Development of A Conceptual Framework for the Adoption and Diffusion of Internet and Web Technologies in Hotel Marketing: A Study of Hotels in Thailand and Australia', Proceedings of the $16^{\text {th }}$ Annual CAUTHE Conference, 6-9 Feb, Melbourne, 27-42.

Kimberly, JR \& Evanisko, MJ 1981, 'Organisational Innovation: The Influence of Individual, Organisational, and Contextual Factors on Hospital Adoption of Technological and Administrative Innovations' Academy of Management Journal, vol. 24, no. 4, pp. 689-713.

Kuan, KKY \& Chau, PYK 2001, 'A Perception-Based Model for EDI Adoption in Small Businesses Using A Technology-Organisation-Environment Framework.', Information \& Management, vol. 38, no.8, pp. 507-521.

Lertwongsatien, C. \& Wongpinunwatana, N 2003, 'E-Commerce Adoption in Thailand: An Empirical Study of Small and Medium Enterprises (SMEs)', Journal of Global Information Technology Management, vol. 6, no. 3, pp. 67-83.

Mclean, V 2005, 'TIG Global, HSMAI Publish First-Ever Distribution Strategy Guide for Hotel Industry', Hotel Online Special Report, Available via http://www.hotelonline.com/News/PR2005_Ist/Jan05_TIGDistributionStrat... accessed by 25 July 2006.

Mistilis, N, Agnes, P \& Presbury, R 2004, 'The Strategic Use of Information and Communication Technology in Marketing and Distribution: A Preliminary Investigation of Sydney Hotels', Journal of Hospitality and Tourism Management, vol. 11, no. 1, pp. 42-55.

Morrison, AM, Stephen, T, Alison, M \& Allison DM 1999, 'Marketing Small Hotels on the World Wide Web', Information Technology \& Tourism, vol. 2, no. 3/4, pp. 97-113.

Moore, GC \& Benbasat, I 1991, 'Development of an Instrument to Measure the Perceptions of Adopting an Information Technology Innovation', Information Systems Research, vol. 2, no. 3, pp. 92-222.

Nunnally, J 1978, Psychometric Theory, McGraw-Hill, New York.

O’ Connor, P \& Frew, AJ 2004, 'An Evaluation Methodology for Hotel Electronic Channels of Distribution', International Journal of Hospitality Management, vol. 23, no. 2, pp. 179-199. 
Paraskevas, A \& Buhalis, D 2002, 'Outsourcing IT for Small Hotels: The Opportunities and Challenges of Using Application Service Providers', Cornell Hotel and Restaurant Administration Quarterly, vol. 43, no. 2, pp. 27-39.

Rogers, EM 1995, Diffusion of Innovations, $4^{\text {th }}$ edn, Free Press, New York.

Scupola, AJ 2003, 'The Adoption of Internet Commerce by SMEs in the South of Italy: An Environmental Technological and Organizational Perspective', Journal of Global Information Technology Management, vol. 6, no. 1, pp. 52-71.

Seyal, AH \& Rahman, MNA 2003, 'A Preliminary Investigation of E-Commerce Adoption in Small \& Medium Enterprises in Brunei', Journal of Global Information Technology Management, vol. 6, no. 2, pp. 6-26.

Sigala, M 2003, 'Developing and Benchmarking Internet Marketing Strategies in the Hotel Sector in Greece', Journal of Hospitality \& Tourism Research, vol. 27, no. 4, pp. 375-401.

Siguaw, JA, Enz, CA \& Namasivayam, K 2000, 'Adoption of Information in U.S. Hotels: Strategically Driven Objectives', Journal of Travel Research, vol. 39, no. 2, pp. 192-201.

Tan, JJ \& Litschert, RJ 1994, 'Environment-Strategy Relationship and its Performance Implications: An Empirical Study of the Chinese Electronics Industry', Strategic Management Journal, vol. 15, no. 1, pp. 1-20.

Tan, M \& Teo, TSH 1998, 'Factors Influencing the Adoption of the Internet', International Journal of Electronic Commerce, vol. 2, no. 3, pp. 5-18.

Tan, M \& Teo, TSH 2000, 'Factors Influencing the Adoption of Internet Banking', Journal of Association for Information System, vol. 1, no. 5, pp. 1-42.

Thong, JYL \& Yap, CS 1995, 'CEO Characteristics, Organisational Characteristics and Information Technology Adoption in Small business', Omega- International Journal of Management Science, vol. 23, no. 4, pp. 429-442.

Thong, JYL 1999, 'An Integrated Model of Information Systems Adoption in Small Businesses', Journal of Management Information Systems, vol. 15, no. 4, pp. 187-214.

Tornatsky, LG \& Fleischer, M 1990, The Process of technological Innovation, Lexington Books.

Tornatsky, LG. \& Klein, KJ 1982, 'Innovation Characteristics and Innovation Adoption Implementation: A Meta-Analysis of Findings', IEEE Transactions on Engineering Management, vol. 29 , no. 1 , pp. $28-45$.

Van Hoof, HB \& Combrink, TE 1998, 'U.S. Lodging Managers and the Internet', Cornell Hotel and Restaurant Administration Quarterly, vol. 39, no. 2, pp. 46-54.

Van Hoof, HB, Ruys, HFM \& Combrink, TE 1999, 'The Use of the Internet in the Queensland Accommodation Industry', Australian Journal of Hospitality Management, vol. 6, no. 1, pp. 11-24.

Wang, S. \& Cheung, W 2004, 'E-Business Adoption by Travel Agencies: Prime Candidates for Mobile ebusiness', International Journal of Electronic Commerce, vol. 8, no. 3, pp. 43-63.

Yeh, RJ, Leong, JK, Blecher, L \& Lai, HHS 2005, 'Analysis of Hoteliers' E-Commerce and Information Technology Applications: Business Travelers' Perceptions and Needs', International Journal of Hospitality \& Tourism Administration, vol. 6, no. 2, pp. 30-61.

Zikmund, WG 2003, Business Research Methods, $7^{\text {th }}$ edn, Thomson, Ohio. 


\section{Appendix 1}

\section{Survey Questionnaires: "Internet and Web Technologies in Hotel Marketing"}

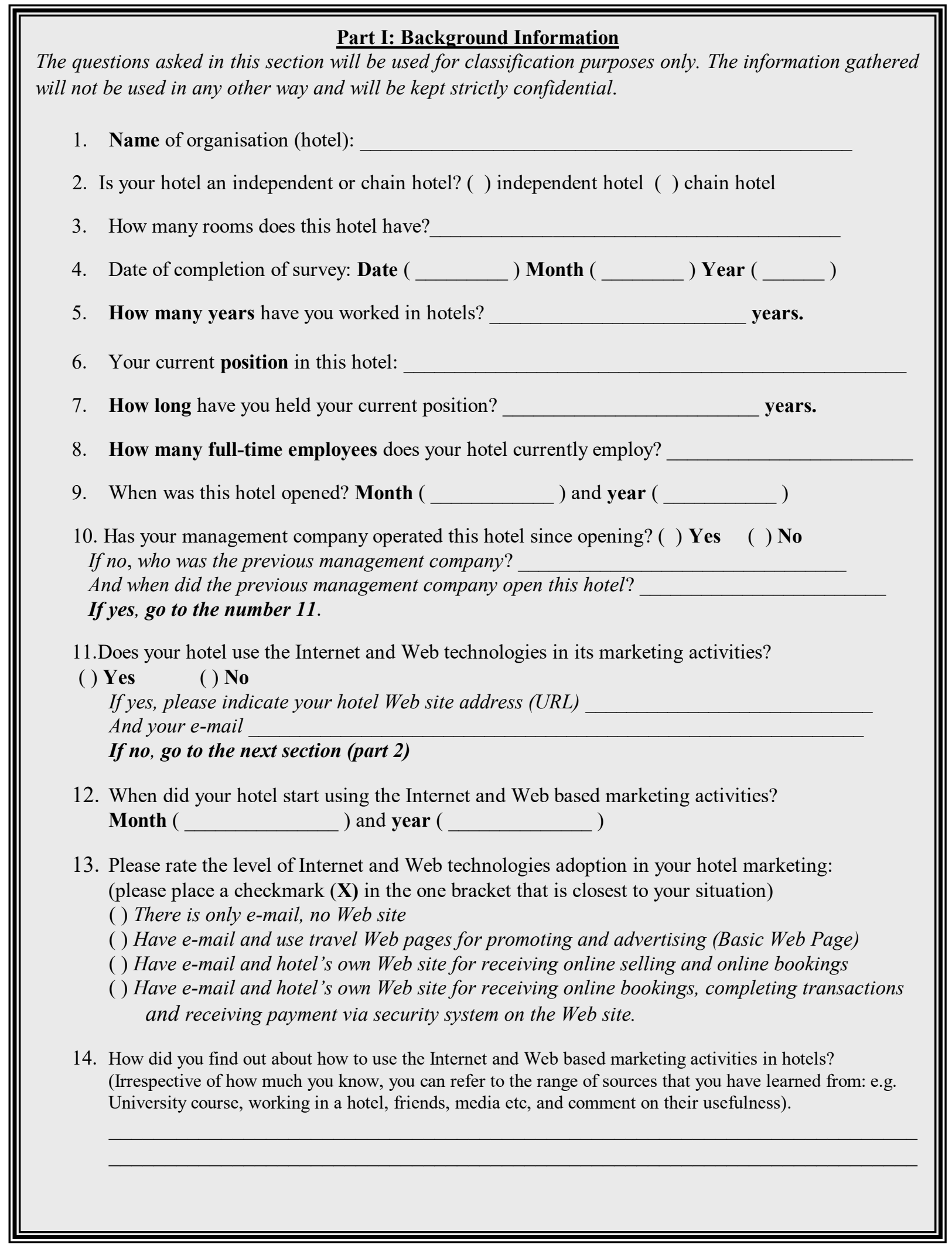


Part II: Factors affecting the adoption of Internet and Web based marketing activities in the hotel industry

Please indicate your level of agreement or disagreement with each of the following statements. For each statement below, please circle the number that best describes your view.
Level of agreement or disagreement
$7=$ Strongly Agree
$6=$ Agree
5 = Slightly Agree
$4=$ Neither Disagree nor Agree
3 = Slightly Disagree
2 = Disagree

\section{Top Management Support for}

Internet and Web based marketing activities

1. Top management considers the Internet and Web based technologies as important.

2. Top management supports, and allocates resources for, the adoption and implementation of Internet and Web based technologies.

3. Top management has effectively communicated its support for the adoption and implementation of Internet and Web based technologies

Complexity, and difficulty in using

Internet and Web based marketing activities

4. Internet and Web based technologies are easy for my employees to use.

5. Internet and Web based technologies are easy for my customers to use.

6. Internet and Web based technologies are clear and understandable for my employees to use.

7. Internet and Web based technologies are clear and understandable for my customers to use.

Attitude towards Internet

and Web based marketing activities

8. My hotel continuously updates information on its Web page.

9. It is very important for my hotel to organise information on its Web page to be reliable, relevant, and accurate.

10. It is very important for my hotel to design a web page with enough information about hotel products to satisfy customers.

11. All hotels will use Internet and Web based technologies in the future.

12. Using Internet and Web based technologies is a fast and efficient way to get more information.

\begin{tabular}{|c|c|c|c|c|c|c|}
\hline \multicolumn{2}{|c|}{$\begin{array}{l}\text { Strongly } \\
\text { Disagree }\end{array}$} & \multicolumn{3}{|c|}{$\begin{array}{l}\text { Neither Agree } \\
\text { Nor Disagree }\end{array}$} & \multicolumn{2}{|c|}{$\begin{array}{l}\text { Strongly } \\
\text { Agree }\end{array}$} \\
\hline 1 & 2 & 3 & 4 & 5 & 6 & 7 \\
\hline 1 & 2 & 3 & 4 & 5 & 6 & 7 \\
\hline 1 & 2 & 3 & 4 & 5 & 6 & 7 \\
\hline 1 & 2 & 3 & 4 & 5 & 6 & 7 \\
\hline 1 & 2 & 3 & 4 & 5 & 6 & 7 \\
\hline 1 & 2 & 3 & 4 & 5 & 6 & 7 \\
\hline 1 & 2 & 3 & 4 & 5 & 6 & 7 \\
\hline \multirow{2}{*}{\multicolumn{2}{|c|}{$\begin{array}{l}\text { Strongly } \\
\text { Disagree }\end{array}$}} & \multirow{2}{*}{\multicolumn{3}{|c|}{$\begin{array}{l}\text { Neither Agree } \\
\text { Nor Disagree }\end{array}$}} & \multirow{2}{*}{\multicolumn{2}{|c|}{$\begin{array}{l}\text { Strongly } \\
\text { Agree }\end{array}$}} \\
\hline & & & & & & \\
\hline 1 & 2 & 3 & 4 & 5 & 6 & 7 \\
\hline 1 & 2 & 3 & 4 & 5 & 6 & 7 \\
\hline 1 & 2 & 3 & 4 & 5 & 6 & 7 \\
\hline 1 & 2 & 3 & 4 & 5 & 6 & 7 \\
\hline 1 & 2 & 3 & 4 & 5 & 6 & 7 \\
\hline
\end{tabular}




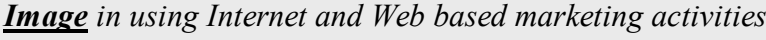

13. Hotels that use Internet technology are more sophisticated than those that do not.

$\begin{array}{lllllll}1 & 2 & 3 & 4 & 5 & 6 & 7 \\ 1 & 2 & 3 & 4 & 5 & 6 & 7\end{array}$

14. Hotels that use Internet technology have higher standards than those that do not.

\section{Customers}

15. My hotel is actively involved in building and maintaining direct customer contacts.

16. Customers are considered an important reason for my hotel to adopt the Internet and Web based technologies.

17. My customers demand the Internet and Web based technologies.

\section{Compatibility of Internet and Web based marketing activities}

18. Using Internet and Web based technologies is compatible with the way my hotel does business.

19. Using Internet and Web based technologies fits well with the way my employees like to work.

20. Use of the Internet to conduct hotel bookings is available to my customers.

21. Use of the Internet to complete transactions is available to my customers. $\begin{array}{llllllll}1 & 2 & 3 & 4 & 5 & 6 & 7\end{array}$

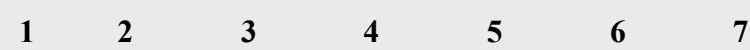

$\begin{array}{llllllll}1 & 2 & 3 & 4 & 5 & 6 & 7\end{array}$

$\begin{array}{llllllll}1 & 2 & 3 & 4 & 5 & 6 & 7\end{array}$

Organisational Readiness of using Internet and Web based marketing activities

\section{My hotel gave its staff formal training} in the use of Internet and Web technologies before it adopted these technologies.

23. The budget was the important factor that my hotel had to deal with before adopting Internet and Web based marketing activities.

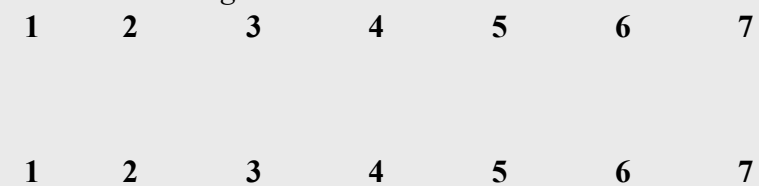

Perceived Benefits of using Internet and Web based marketing activities

24. My hotel can increase sales and enlarge market $\mathbf{1}$ share by using Internet and Web based technologies.

25. My hotel can reduce operating costs by using Internet and Web based technologies.

26. My hotel can extend market reach by using Internet and Web based technologies.

27. My hotel can improve customer service by using Internet and Web based technologies. 


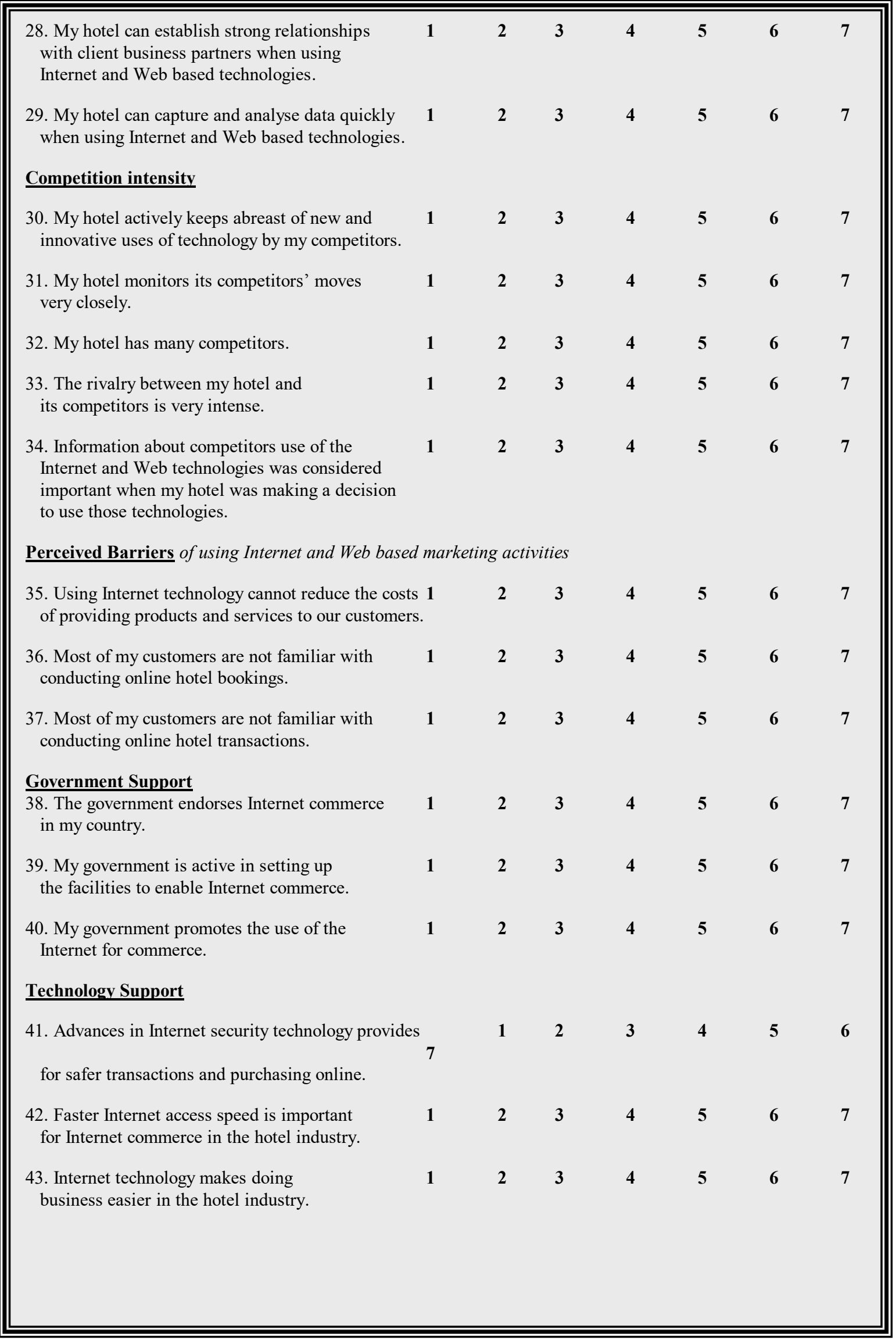




\section{Information System Knowledge}

44. Please indicate your highest level of education by using a checkmark ( $\mathbf{x}$ )

( ) TAFE/ Commercial College

( ) Bachelor's

( ) Master's

( ) Ph.D

Please indicate your level of using Internet and web technologies by circling the number on the scale with each of the following statements:

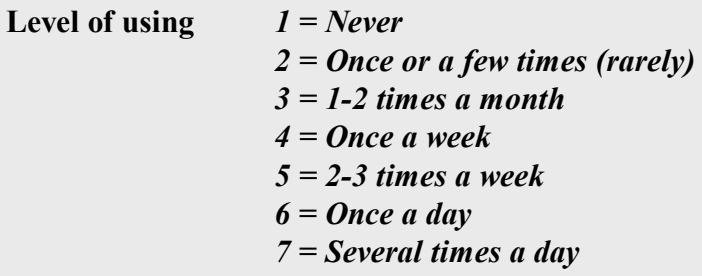

45. I use e-mail to communicate with

Never

Several times a day

my employees in my hotel.

46. I use e-mail to contact my customers

inside the country.

47. I use e-mail to contact my customers outside the country.

48. I use online (WWW) resources to

$$
1
$$$$
3
$$

$3-4$

4

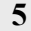

6 7 find information relevant to hotel business.

49. I use a computer at my hotel office.

50. I use a computer at my residence.

$\begin{array}{lll}1 & 2 & 3 \\ 1 & 2 & 3\end{array}$

Please indicate your level of understanding of how to use the Internet and Web for marketing activities by circling the number on the scale that best describes your view.

51. I have a very good understanding of how to

1 use the Internet and Web for marketing activities. 


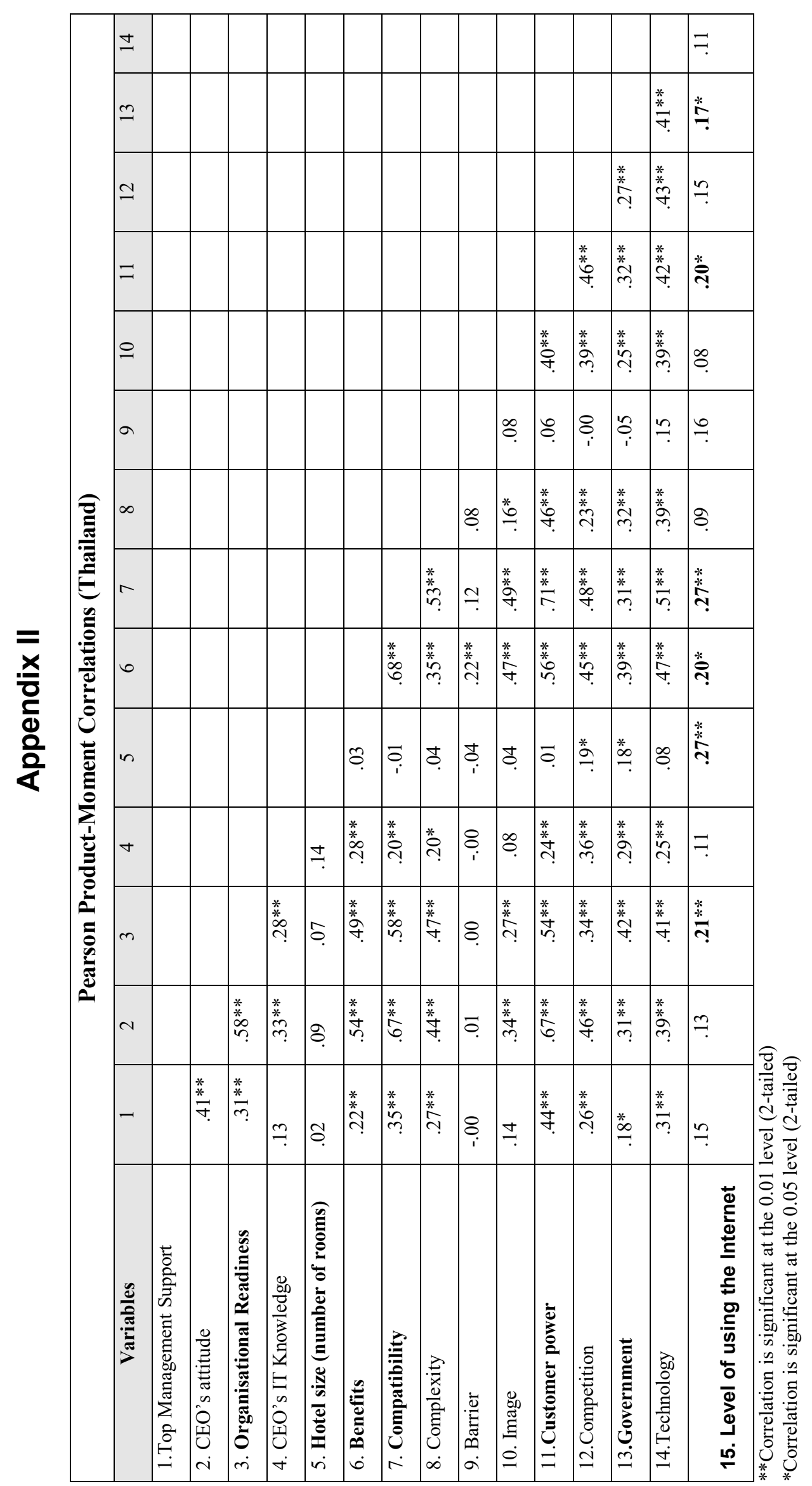

